\title{
Influence of Oxygen Addition on Structure and Properties of Titanium Produced by Electroslag Remelting
}

\author{
Olga Snizhko', Anatoliy Ryabtsev¹, Alexandr Troyanskyy¹, Vladimir Pashinskii1, \\ Bernd Friedrich $^{2}$, Johannes Morscheiser ${ }^{2}$, Marek Bartosinski ${ }^{2}$ \\ ${ }^{1}$ Department of Electrometallurgy, Donetsk National Technical University, Donetsk, Ukraine \\ ${ }^{2}$ IME Process Metallurgy and Metal Recycling, RWTH Aachen University, Aachen, Germany \\ Email: rato@fizmet.dgtu.donetsk.ua,bfriedrich@ime-aachen.de
}

Received 16 September 2015; accepted 6 March 2016; published 9 March 2016

Copyright (C) 2016 by authors and Scientific Research Publishing Inc.

This work is licensed under the Creative Commons Attribution International License (CC BY). http://creativecommons.org/licenses/by/4.0/

(c) (i) Open Access

\begin{abstract}
The current work is devoted to the investigation of oxygen impact on the structure and properties of titanium. For this purpose, oxygen was introduced into titanium during chamber electro-slag remelting by three different methods: alloying by oxygen-rich residues from the Kroll process to final values between $0.053 \mathrm{wt} .-\%$ and $0.40 \mathrm{wt}$. $\%$, by reaction with the gas phase to $0.27 \mathrm{wt} .-\%$ and by introduction of $\mathrm{TiO}_{2}$ nanoparticles to $0.73 \mathrm{wt} . \%$. The influence of oxygen on microstructure of titanium during crystallization, heat treatment and deformation is determined as well as the effect of oxygen on the hardness and the mechanical properties of the material in different structural states. Furthermore, control methods of the structure formation process by thermal effects are proposed. Results show that the chamber electroslag remelting allows obtaining a homogeneous structure of the ingot in the investigated range of oxygen content in titanium. The hardness does not vary by more than 10 percent in longitudinal or radial direction in any of the remelted ingots.
\end{abstract}

\section{Keywords}

Titanium, Oxygen, Electroslag Remelting, Alloying, Heat-Treatment, Shear Transformation, Recrystallization, Deformation Work-Hardening, Structure Refinement

\section{Introduction}

Among structural materials, titanium and its alloys occupy a special position. Due to its properties, titanium is considered as a basic structural material for many industries, including the medical sector. In the latter case, beside high specific strength and resistance to impact loading, the most important requirements for medical tita-

How to cite this paper: Snizhko, O., Ryabtsev, A., Troyanskyy, A., Pashinskii, V., Friedrich, B., Morscheiser, J. and Bartosinski, M. (2016) Influence of Oxygen Addition on Structure and Properties of Titanium Produced by Electroslag Remelting. Materials Sciences and Applications, 7, 139-149. http://dx.doi.org/10.4236/msa.2016.73014 
nium alloys are corrosion resistance, biocompatibility and the absence of toxic elements.

The most common titanium alloy for medical applications is Ti-6Al-4V (Grade 5). However, under certain conditions, the presence of vanadium in this alloy can lead to the formation of toxic compounds in the human body [1]. To eliminate this drawback, vanadium can be replaced by a safer alloying component, oxygen in particular. In contrast to nitrogen and hydrogen, oxygen can lead not only to negative, but also positive effects on the properties of titanium. Thus, small amounts of oxygen can be considered as an economical alloying element that increases the strength of titanium. By controlling its content in the metal, it is possible to reach the optimal ratio of plasticity and strength characteristics of the material. In this case, it is very important to ensure uniform distribution and desirable form of oxygen in the metal. This is achieved by applying appropriate technologies for melting and heat treatment. For this purpose, the chamber electroslag remelting (ChESR) process can be used. In addition to refining in a controlled atmosphere, this process offers the possibility of additional alloying during remelting. The alloying step can be done from both the gas phase and by adding different alloying elements in the solid state. ChESR provides, as well as other remelting processes, a good structural and chemical homogeneity of the ingots with a typical as-cast structure [2]-[9].

However, it is important to determine whether oxygen should be presented as a solid oxide or atomically dissolved in the metal. Based on the influence of this condition on structural and phase transformations, it is necessary to determine the optimal oxygen content, as well as the ideal temperature ranges for the heat treatment. Insufficient knowledge of the structure and properties of electroslag remelted titanium with increased oxygen levels, as well as the impact of different heat treatment methods is currently preventing the wide application of these materials as a substitute for expensive and comparatively unsafe alloys like Ti-6Al-4V.

This paper discusses the effect of oxygen and the heat treatment on the microstructure and properties of titanium produced by chamber electroslag remelting. The purpose of the paper is to accumulate fundamental knowledge about structure and properties of oxygen-alloyed titanium produced by the ChESR process. Accordingly, methods for controlling the structure formation by thermal and deformation effects are developed.

\section{Experimental}

As mentioned before, in the present work the ChESR process was used to produce oxygen-alloyed titanium. Three different oxygen-bearing additives were used in the experimental part:

- Reaction mass residues from the retort lid of the Kroll process [10].

- A continuous gas flow of specially prepared argon-oxygen mixture containing 30\% oxygen through the remelting zone [11]-[13].

- Titanium oxide particles with a grain size of 10 - $15 \mathrm{~mm}$ and titanium oxide nanopowder with a grain size of $21 \pm 5 \mathrm{~nm}$ (addition to the slag or to the electrode) [14].

The remelted electrodes were pressed from titanium sponge grade TG-90 and TG-110 with a diameter of 40 - 80 $\mathrm{mm}$ and a length of $600 \mathrm{~mm}$. The mold diameter was 60 and $110 \mathrm{~mm}$ respectively depending on the used furnace.

The obtained titanium ingots is contained oxygen up to $0.40 \mathrm{wt}$.- $\%$ when alloyed by the reaction mass residues mixture, up to 0.27 wt.-\% by alloying from the gas phase and up to 0.73 wt.-\% by introducing $\mathrm{TiO}_{2}$ nanopowder to the slag or to the electrodes. Samples were cut off from the ingot in order to perform a chemical analysis and metallographic studies.

Metallographic investigations at magnifications from $\times 50$ to $\times 5000$ were carried out on optical microscopes (Axiovert 40 MATCarl Zeiss and Neophot 2), an electron microscope (JEOL JSM-6490LV JEOL, Japan) equipped with an energy dispersive spectrometer (INCA Penta FETx3, Oxford Instruments, England), a wave spectrometer (INCA Wave, Oxford Instruments, England) and a backscattered electron diffraction detector (HKL, Oxford Instruments, England).

The chemical composition of the metal was determined with an optical emission spectrometer (SPECTROMAX, SPECTRO, Germany). The gas content was determined in the laboratories of the E.O. Paton Institute of Electric Welding of the National Academy of Science of Ukraine, Zaporozhye titanium and magnesium plant and RWTH Aachen University, Germany on different analyzers (TN-114, RO-316, RH-2, RH-3, Ströhlein O/N-MAT 8500).

Mechanical tests and measurements of hardness were carried out by standard methods.

\section{Results and Discussion}

In the first stage, titanium samples alloyed by the reaction mass residues mixture were investigated. An analysis 
of the hardness distribution shows that the hardness increases with increasing oxygen contents in the metal from $130 \mathrm{HB}$ at $0.07 \mathrm{wt} .-\%$ oxygen to HB 350 at $0.40 \mathrm{wt} .-\%$. In the radial direction (from center to surface), the hardness in all ingots and at all heights remains roughly constant, indicating a uniform distribution of impurities and alloying elements. With increasing oxygen content in the metal, the strength increases from $380 \mathrm{MPa}$ at 0.07 wt.-\% oxygen to $708 \mathrm{MPa}$ at 0.4 wt.-\%.

The microstructure of titanium containing 0.07 oxygen consists of $\alpha$-phase, whereas an oxygen content of $0.40 \mathrm{wt} .-\%$ leads to the formation of $\alpha^{\prime}$-phase (Figure 1).

Increasing the oxygen content to 0.3 wt.- $\%$ does not lead to a significant change in the morphology of the $\alpha$-phase. With further increase of oxygen to $0.4 \mathrm{wt} .-\%$ the microstructure shows a typical needle character that allows to classify it as $\alpha$-phase. The formation of this structure is accompanied by a sharp increase in hardness. However, it should be noted that during mechanical tests of the ingot produced by remelting the reaction mixture from the Kroll process containing $0.40 \mathrm{wt} . \mathrm{\%}$ oxygen were fractured without any elongation. Samples with an oxygen level of $0.30 \mathrm{wt.}$. $\%$, produced by remelting an electrode containing $50 \%$ titanium sponge and $50 \%$ reaction mixture, have a very small breaking elongation (11\% compared with the required $20 \%$ for ASTM Grade 1 titanium).

This is because the reaction mixture contains an increased amount of impurities compared to the utilized titanium sponge. For example, the nitrogen content is ten times higher $(0.011 \%$ in the sponge and $0.11 \%$ in the reaction mass), the iron content is almost twice as high (0.06\% in the sponge and $0.09 \%$ in the reaction mass) and the amount of carbon is four times higher $(0.004 \%$ and $0.16 \%$ respectively). Oxygen has an impact on the morphology of the phases and can significantly increase the hardness and strength of titanium in the as-cast condition. This type of oxygen bearing additive can be used for commercial pure titanium with a relatively low (0.25 wt.-\%) content of oxygen, such as Grade 1 and Grade 2. In the next stage of the current work, samples alloyed with oxygen from the gas phase with concentrations from 0.053 wt.- $\%$ to 0.27 wt.- $\%$ were investigated. As in the previous case, the hardness correlates well with the oxygen content in the metal and increases with increasing oxygen contents (Figure 2).

The strength of the material is increased from $400 \mathrm{MPa}$ at $0.053-0.075$ wt.-\% oxygen to $795 \mathrm{MPa}$ at 0.27 wt.- $\%$ with decreasing of plasticity in the range from $25 \%$ to $3 \%$. In the as-cast state, the metal has a homogeneous single-phase structure, but its morphology depends on the oxygen content. Thus, the microstructure of the metal with an oxygen content of 0.053 wt.- $\%$ is typical for technical titanium. A typical $\alpha$ '-phase with needle character can be noticed at increased oxygen contents up to $0.22 \mathrm{wt} .-\%$. In this case the needle $\alpha$-phases have a length of 200 - 400 microns.

This is due to the fact that during the $\beta \rightarrow \alpha$ transformation development of the shear mechanism the $\alpha$ '-phase crystals grow inside the initial large dendritic $\beta$-phase crystals (Figure 3). The formation of this structure is accompanied by a sharp increase in hardness.

The formation of the needle structure can be explained as follows: it is known that the $\alpha$-phase is formed from the $\beta$-region at accelerated cooling rates. Since the thermal regime in the process can be considered as constant during remelting, the transition to the formation of shear structures may occur due to the increased stability
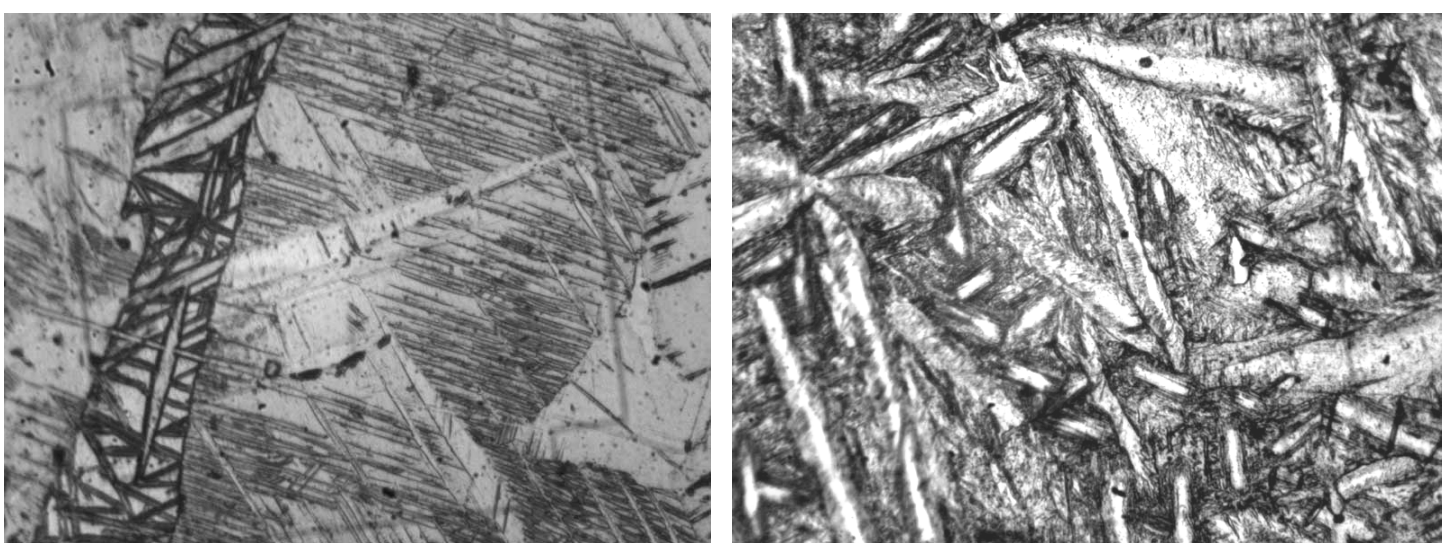

Figure 1. Microstructure of electroslag remelted titanium samples made of reaction residues, left: 0.07 wt.-\% oxygen; right: 0.4 wt. $-\%$ oxygen, magnification $\times 500$. 


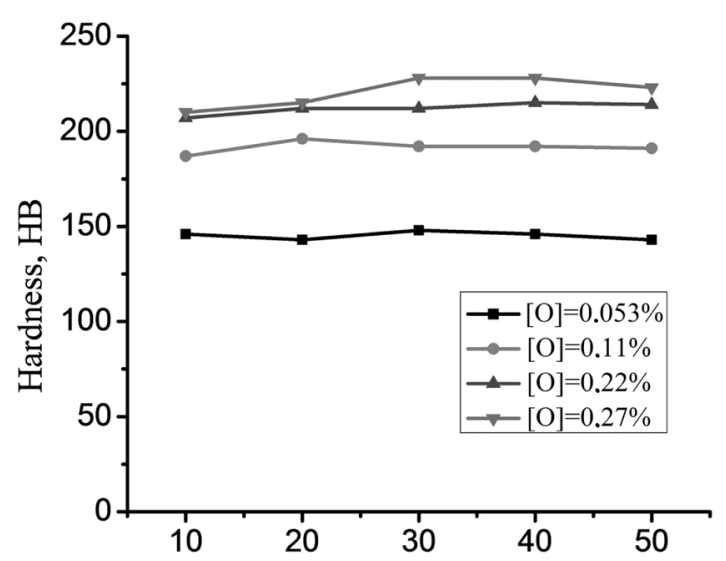

The distance along the diametric section of the ingot, $\mathrm{mm}$

Figure 2. The distribution of hardness in the samples of as-cast titanium, depending on the oxygen content.
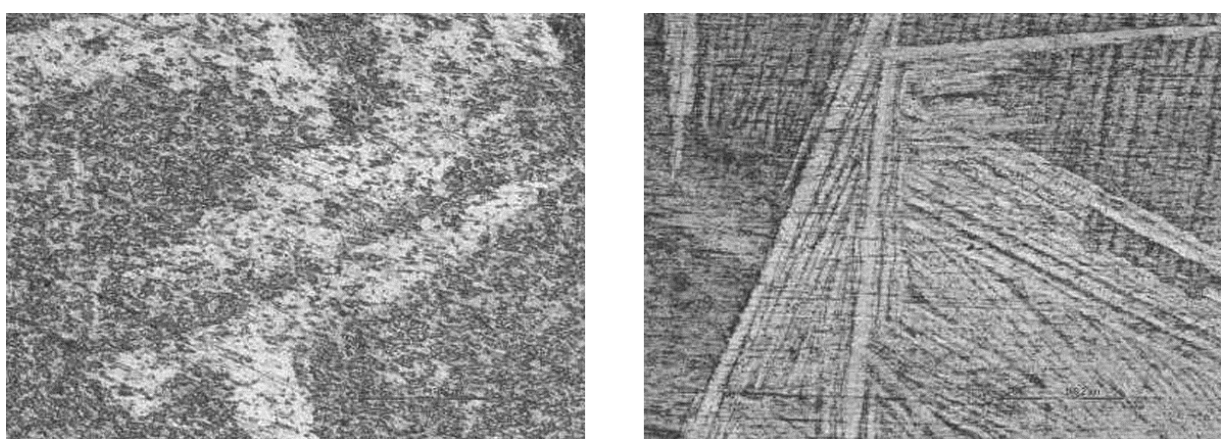

Figure 3. The structure of as-cast titanium after oxygen pickup from the gas phase, left: 0.075 wt.- $\%$ oxygen; right: 0.27 wt.- $\%$ oxygen, magnification $\times 100$.

of the supercooled $\beta$-phase with increasing oxygen contents. Therefore, the higher the $\beta$-phase stability under conditions of continuous cooling, the lower the temperature range of the $\beta-\alpha$ transformation and hence, the probability of the shear transformation development increases.

The assumption that the influence of oxygen on the structure formation during the $\beta \rightarrow \alpha$ transformation is associated with a change of the transformation rate is confirmed by the metal structures in the annealed and quenched states (Figure 4).

As Figure 4 shows, the metal structure after annealing consists of large elongated and oriented grains. With increasing oxygen contents in the investigated range, the grain size increases by the factor of 3.5 to 4 . In all samples a dispersed acicular structure after quenching is observed. In quenched condition titanium with oxygen levels below $0.11 \mathrm{wt} .-\%$, the needles of $\alpha$ '-phase grow predominantly inside the large polyhedral grains of initial $\beta$-phase. Former boundaries of these grains are represented by thin layers of light-colored phase. At the oxygen contents of $0.11 \mathrm{wt.}$ - $\%$ and higher the etchability of the needles increases.

In this paper the assumption was made, that the oxygen-hardening of titanium is a consequence of the supersaturated solid solution formation and subsequent precipitation of dispersed particles. Based on the analysis of the phase diagrams which were published by different authors [15]-[17], it can be concluded that the precipitation of excess phases is possible at temperatures below $600^{\circ} \mathrm{C}$. According to this, a heat treatment method was developed, which consisted of annealing, quenching at $1100^{\circ} \mathrm{C}$ and aging at $150^{\circ} \mathrm{C}, 350^{\circ} \mathrm{C}$ and $500^{\circ} \mathrm{C}$. Investigations on the effect of aging parameters on the hardness show that there is practically no correlation between hardness and exposure time (Figure 5). This is probably due to the fact that in the investigated samples the precipitates are not formed as the conducted microstructural investigations show.

After quenching the samples with oxygen contents less than $0.11 \mathrm{wt} .-\%$ a finely divided acicular structure was found. In it the grain boundaries were revealed, which are represented by layers of the light phase.

Since these boundaries do not correspond to structural elements which can be observed in the annealed 


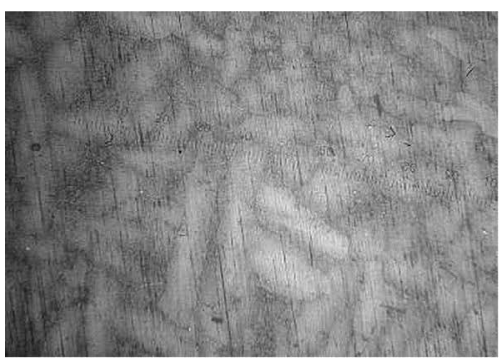

(a)

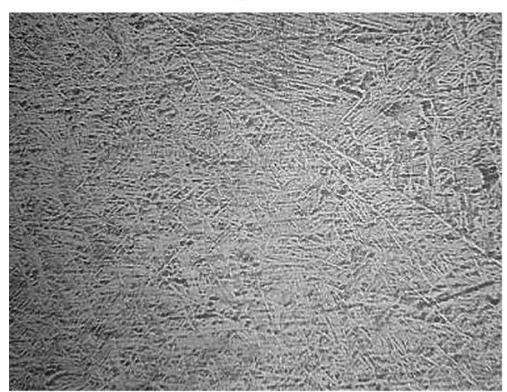

(c)

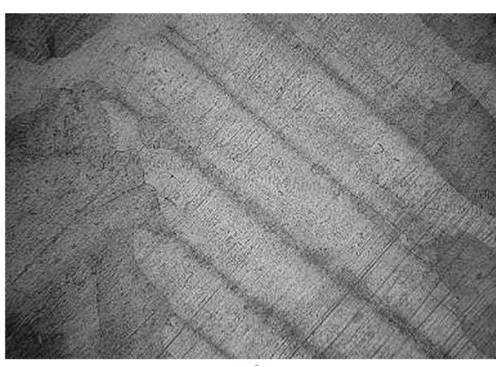

(b)

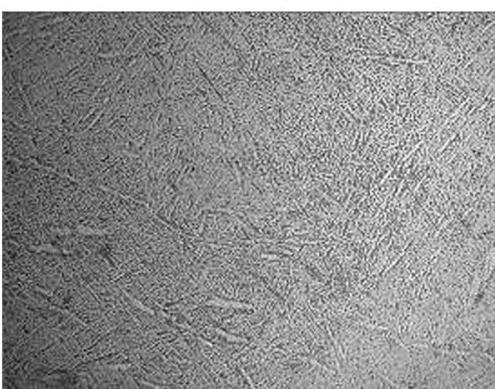

(d)

Figure 4. The structure of electroslag remelted titanium alloyed with oxygen from the gas phase, after annealing ((a), (b)) and quenching ((c), (d)). (a), (c): 0.075 wt.-\% oxygen; (b), (d): 0.22 wt.-\% oxygen, magnification $\times 100$.

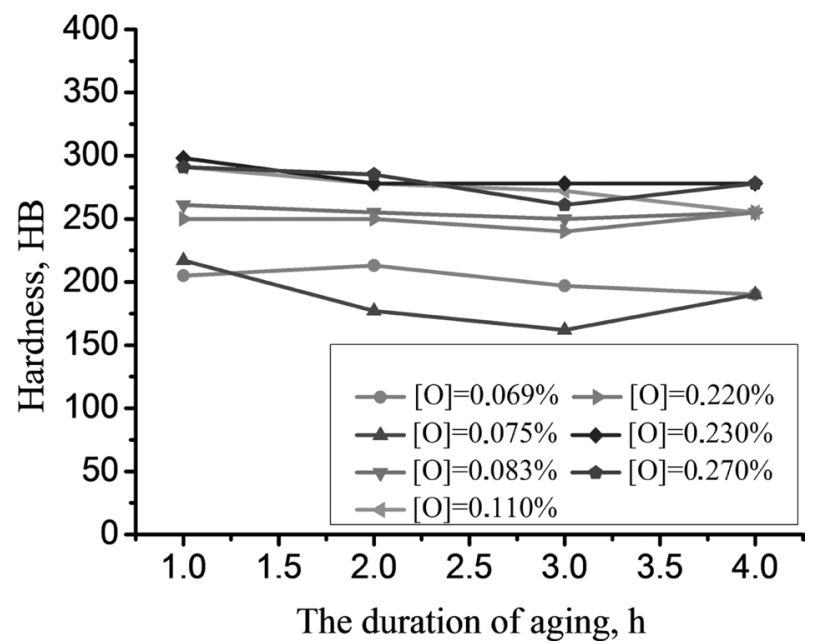

Figure 5. Hardness of titanium with different oxygen contents after aging at $350^{\circ} \mathrm{C}$ as a function of exposure time.

condition, it can be assumed that they are former grain boundaries of the $\beta$-phase. The aging step reduces the contrast of the etching of the needle structure and the needle contour becomes dashed, which may be associated with recrystallization processes within the hardened structure of the shear transformation.

In samples with oxygen contents above 0.11 wt.- $\%$, the observed differences can be explained by the needle structure formation after quenching. After aging, the contrast of the needles after etching is increasing and they are detected in all areas of the structure. A blurring of the needle boundaries is not detectable, that indicates a decrease of the recrystallization rates under the influence of higher oxygen contents. The size of the needles is higher than in the metal with low oxygen content.

Considering that the optical metallography did not reveal dispersed particles, investigations by scanning electron microscopy were conducted. Figure 6 shows photographs in the backscattering electron mode, in which the measured contrast depends on the atomic number of a chemical element, at magnifications $\times 1000$ to $\times 5000$. After etching, a pattern from light and dark areas appears at the surface of the sample. However, the results of the chemical analysis by SEM-EDX do not reveal a statistically significant correlation between concentrations of 
the elements and details of the observed structure. It is suggested that the visible pattern at high magnification is due to non-uniform etching and does not represent the actual structure of the metal. Therefore, the study was repeated on the same samples in the non-etched condition. As Figure 6 shows, the contrast does not arise when investigating non-etched samples in the backscattering mode. This suggests that the reason for the contrast development in those samples is non-uniform etching.

In general, the formation of inclusions is not observed in the investigated samples at magnifications up to $\times 5000$. The absence of dispersed precipitates means that oxygen is in solid solution. In this case, it must have an effect on the temperature of the $\alpha-\beta$ phase transformation. In order to prove this assumption, the samples containing $0.053 \mathrm{wt} .-\%$ and $0.27 \mathrm{wt} .-\%$ oxygen were quenched from the temperature $910^{\circ} \mathrm{C}$. For pure titanium this temperature corresponds to $\beta$-modification. In the sample with a low oxygen concentration a homogeneous microstructure was formed, but in the sample with a high oxygen concentration the microstructure consisted of large elongated oriented crystals with a different etching (presumably $\alpha+\alpha$ ). The formation of such a structure is explained by the fact that at this temperature due to the influence of oxygen the temperature of the phase transformation increases and the metal is in a $\alpha+\beta$ phase region according to the phase diagram of Ti-O.

Thus, the structure and properties investigation of titanium samples alloyed with oxygen from the gas phase in the ChESR furnace shows that this remelting process provides good chemical and structural homogeneity of the metal. Furthermore, the results show, that after the heat treatment step no precipitation of dispersed particles did occur and oxygen is in solid solution in the investigated samples.

Within this presented experimental work, the effects of $\mathrm{TiO}_{2}$ as an oxygen-bearing additive on the structure and properties of electroslag remelted titanium were investigated. The utilized $\mathrm{TiO}_{2}$ was added in the form of micro- and nanopowder. Ingots with oxygen contents from $0.30 \mathrm{wt.} \%$ to $0.73 \mathrm{wt.}-\%$ were obtained. As Figure 7 shows, the application of $\mathrm{TiO}_{2}$ powder leads both to an increase of the oxygen content in the metal as well as to changes of the structure and hardness. In the sample containing 0.09 wt.-\% oxygen (reference melt without adding titanium oxide) an equiaxed, coarse-grained structure can be observed. In the samples with oxygen contents of 0.57 wt.-\% and 0.73 wt.-\% it has a needle-shaped morphology. In the sample alloyed with TiO2 nanopowder, the microstructure is more dispersed at the same content of oxygen.
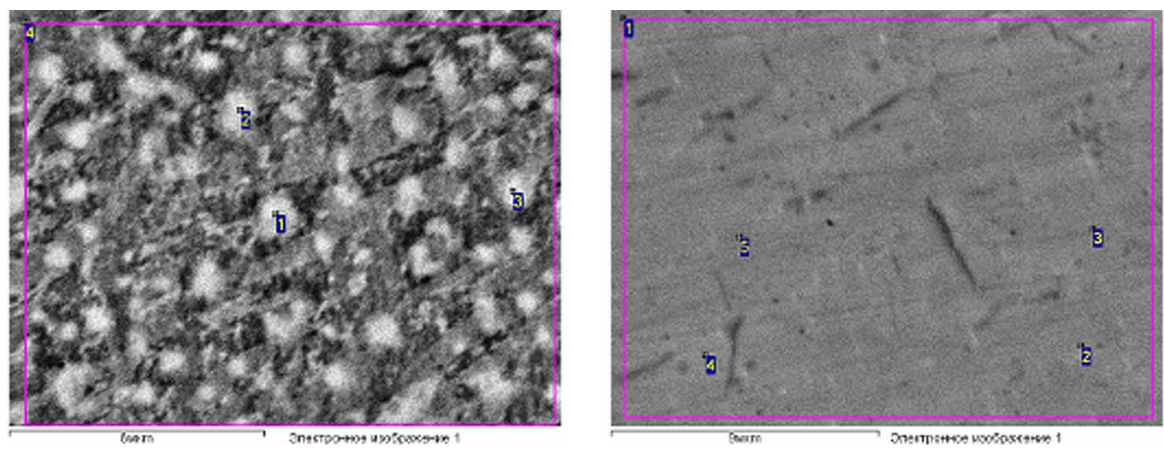

Figure 6. Raster image of the sample-surface containing 0.27 wt.-\% oxygen in backscattering electron mode after (left) and before etching (right), magnification $\times 5000$.

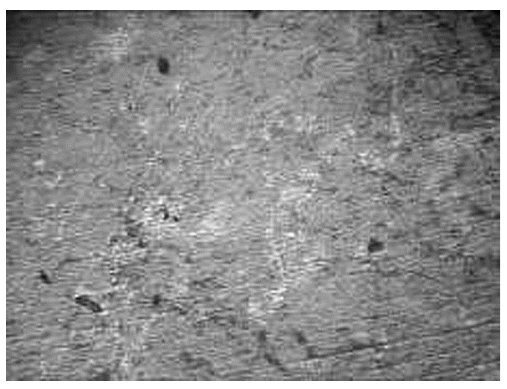

(a)

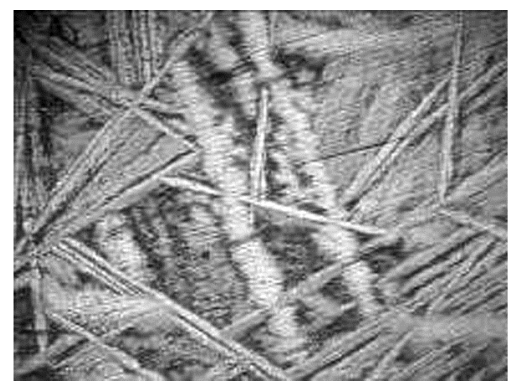

(b)

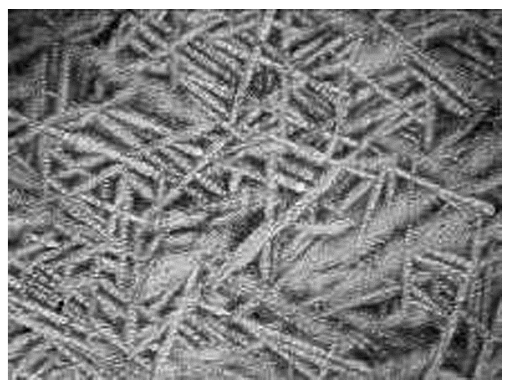

(c)

Figure 7. The structure of electroslag remelted titanium: (a) reference, (b) and (c) alloyed with titanium oxide powder ((b) microsize, (c) nanosize), magnification $\times 100$. (a) 0.09 wt.- $\%$ oxygen; (b) 0.57 wt.- $\%$ oxygen; (c) 0.73 wt.- $\%$ oxygen. 
The structural changes of titanium after ChESR with additives of $\mathrm{TiO}_{2}$ powders have a significant impact on its hardness. While titanium after ChESR without oxygen additions has a hardness of $125 \mathrm{HB}$, this value increases from 205 to $295 \mathrm{HB}$ with increasing oxygen contents from 0.30 to $0.73 \mathrm{wt} .-\%$ respectively.

At the same oxygen concentration in the electrodes, the measured values for the nanopowder melts were slightly higher (295 HB) in comparison to the use of micro powder (285 HB) as oxygen bearing additive.

In the next stage, the characteristics of structural transformations in the obtained titanium samples were investigated. The influence of oxygen on the structure during thermal treatment and deformation is shown. Since the previous studies did not reveal any formation of particles during crystallization and heat treatment of titanium, it is suggested that oxygen remains in solid solution. In this case, it should affect the temperature of the polymorphic transformation from $\alpha \rightarrow \beta$ phase.

In a series of quenching from gradually changed temperatures, the start and end temperatures of the above mentioned phase transformation for the samples alloyed with oxygen from the gas phase to the contents of 0.053 wt.- $\%$ and 0.27 wt.- $\%$ were identified. According to the microstructural changes in the sample containing 0.053 wt.-\% oxygen, the beginning of the polymorphic transformation occurs at $920^{\circ} \mathrm{C} \pm 5^{\circ} \mathrm{C}$ with a transformation temperature range no more than $15^{\circ} \mathrm{C}$. The equivalent start and end temperatures for the sample containing 0.27 wt.-\% oxygen are $935^{\circ} \mathrm{C} \pm 5^{\circ} \mathrm{C}$ and $985^{\circ} \mathrm{C} \pm 5^{\circ} \mathrm{C}$. The obtained data confirms that oxygen in the investigated concentrations does not form stable compounds in the titanium. As a conclusion, in the temperature range from $870^{\circ} \mathrm{C}$ to $1000^{\circ} \mathrm{C}$ oxygen is in solid solution.

It is established that with increasing oxygen contents the morphology of the titanium structure is changing from polyhedral to needle-shape. Simultaneously, within the complete investigated range of oxygen concentrations, the structure of the metal is single-phase and the precipitates of excess phases are not observed. This can be caused by the non-equilibrium nature of the crystallization process caused by the relatively high cooling rates in a water-cooled mold during electroslag remelting. For obtaining the equilibrium structure, samples of the produced titanium were annealed at $1100^{\circ} \mathrm{C}$ (in the temperature range of $\beta$-phase stability) and cooled within the furnace.

Coarse elongated grains form the structure with different etchability. With increasing oxygen content, the specific area occupied by the light colored grains increases. The difference in etchability may be correlated with the formation of different phase constituents of the same phase but with different composition. To check this assumption, X-ray analyses of the samples with oxygen contents of 0.053 wt.- $\%$ and 0.27 wt.-\% were carried out with additional micro hardness measurements of the structural components.

The results of the X-ray analysis show that, despite the formation of a heterogeneous structure in terms of phase composition, the samples are single phase and have a hexagonal lattice $\alpha$-modification of titanium. The results of micro hardness measurements are shown in Figure 8.

It can be seen, that the micro hardness of the dark constituent in both samples is constant at 2760 - $2850 \mathrm{MPa}$. That of the light constituent is significantly higher and varies depending on the oxygen content in the titanium. Statistically, its value increases considerably with increasing oxygen content. This observation might be explained by a stratification of solid solution of oxygen in the $\alpha$-Ti into two components at room temperature, since the parameter of the hexagonal lattice $\mathrm{c}$ of titanium alloyed by oxygen is slightly higher than that of pure
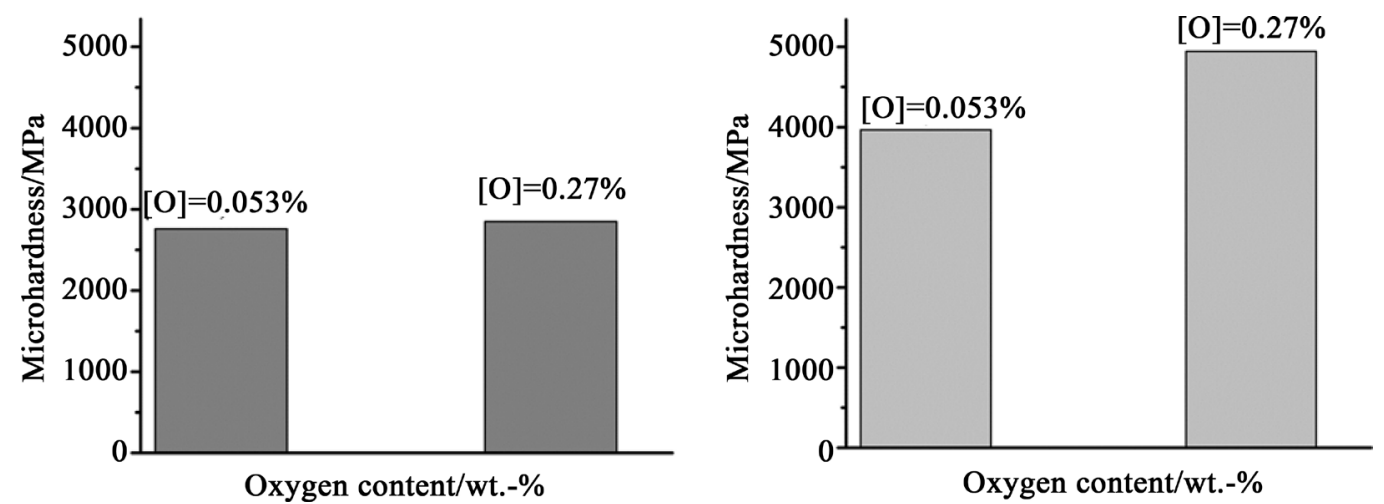

Figure 8. The microhardness of structural constituents in titanium alloyed by oxygen: left-dark constituent, right-light constituent. 
titanium (0.4686 nm compared to $0.4679 \mathrm{~nm}$ ) [18]-[20].

An analysis of the obtained data shows that the stratification of the solid solution can lead to further hardening of the metal but increases the risk of brittle fracture at the same time. Considering this, the structure of the fracture of samples with different oxygen contents, which were obtained after tensile tests, were analyzed. As can be seen in Figure 9, the fracture has a ductile nature at the oxygen content of $0.053 \mathrm{wt.}$-\%.

The investigation of the microstructure in areas which adjoin to the fracture surface shows, that at low oxygen contents $(0.053 \mathrm{wt.}$ - $\%)$ there is no dependence between orientation of grains and direction of crack development. The fracture has a typical transcrystalline character. An oxygen content of $0.11 \mathrm{wt} .-\%$ leads to the appearance of brittle areas in the fracture surface. Some parts of the fracture surface become associated with grain-oriented groups of "basket weave", though the destruction is not absolutely brittle and the fracture surface passes through such groups. With further increase of the oxygen content to $0.22 \mathrm{wt} . \mathrm{\%} \%$, the fracture becomes more brittle and the orientation of its surface changes. However, in the surface, the brilliant facet of intercrystalline fracture is practically not visible. It remains matt with a strong relief, consisting of differently oriented areas of destruction. At the oxygen concentration of $0.27 \mathrm{wt} . \mathrm{-} \%$, a change of the nature of the fracture is observed, inasmuch as extended areas of the fracture pass along the grain boundaries.

Thus, the increasing oxygen content leads to a change in the morphology of the microstructure of the metal, which leads to brittle fracture during tension. The main influencing factor is the formation of a coarse structure. In this case it is necessary to carry out heat treatments which refine the microstructure in order to increase the plasticity. However, it cannot be excluded that on the grain boundaries an allocation of excess phases appears which embrittles the boundary.

Since the issue about phase and structural composition of titanium alloyed by oxygen at low temperatures is studied insufficiently in the literature, an investigation of the fracture characteristics of such alloys was carried out. Ingots with an oxygen content of 0.053 and $0.27 \mathrm{wt} .-\%$ respectively were exposed to influence damage at a temperature of $-196^{\circ} \mathrm{C}$ in order to obtain a brittle fracture and to identify the structural details, which are conducive to the development of failure.

Figure 10 shows SEM photographs of the fracture surface of titanium samples with different oxygen contents.

It can be seen, that at high oxygen contents the fracture is brittle. The fracture of the titanium sample with a low content of oxygen is mixed: it contains both parts of the ductile cellular destruction, as well as parts of quasi-brittle and brittle fracture. At the same time, the attention is drawn to the fact that in all the investigated surfaces no second-phase particles were observed which are responsible for the development of fracture processes. Therefore, the failure is associated with the formation of coarsened as-cast structure. These observations are confirmed by the results of fractographic studies by TEM (Figure 11).

In final products, titanium alloys are mainly used after mechanical processing and heat treatment. Therefore, from a practical point of view it is very important to determine the effect of oxygen on the structure formation of the metal after such exposures. For example, Figure 12 depicts that the shear transformation during quenching from temperatures of $\beta$-phase stability. The quenching leads to the formation of dispersed acicular crystallites that grow inside the primary grains of the $\beta$-phase.

The growing needles are mutually blocking their own growth and therefore smoothen the differences in the size of the structural elements, which is typical for the annealed condition. Therefore, the negative effect of oxygen on the structure of the metal can be counterbalanced by subsequent heat treatment. The increased oxy-

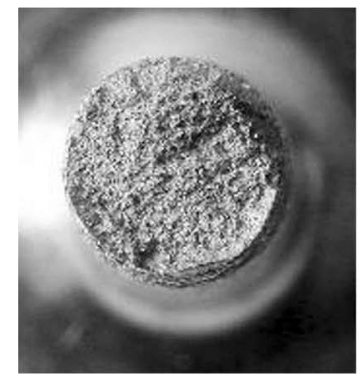

$\lceil\mathrm{O}]=0.053 \mathrm{wt} . \mathrm{-} \%$

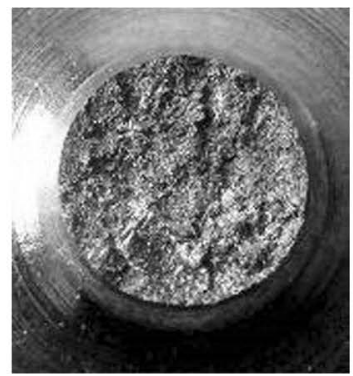

$\lceil\mathrm{O}]=0.11 \mathrm{wt} . \mathrm{-} \%$

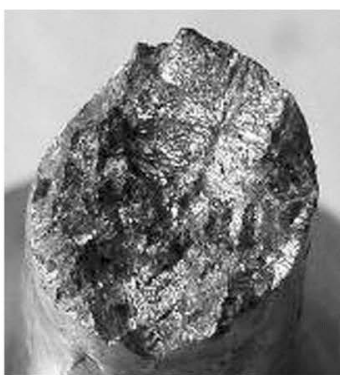

$\lceil\mathrm{O}\rceil=0.22 \mathrm{wt} . \mathrm{-} \%$

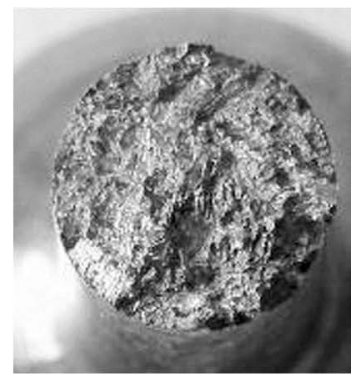

$\lceil\mathrm{CO}=0.27$ wt. $-\%$

Figure 9. Fracture surface of titanium samples (alloyed with oxygen from the gas phase). 


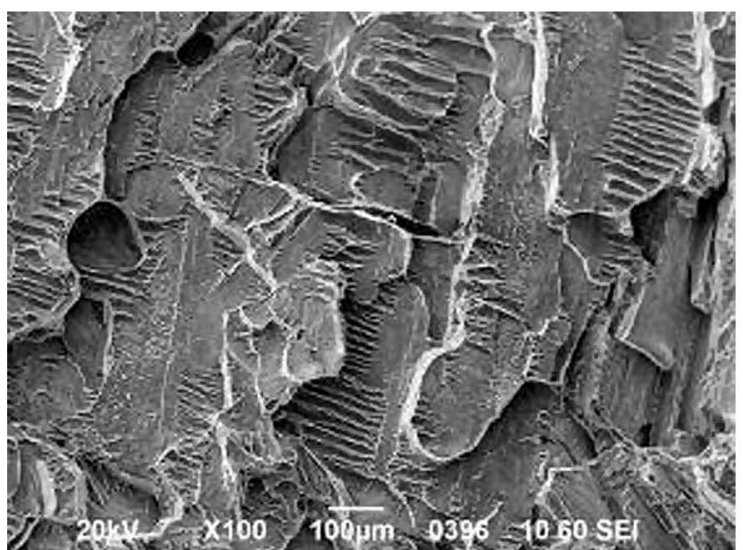

(a)

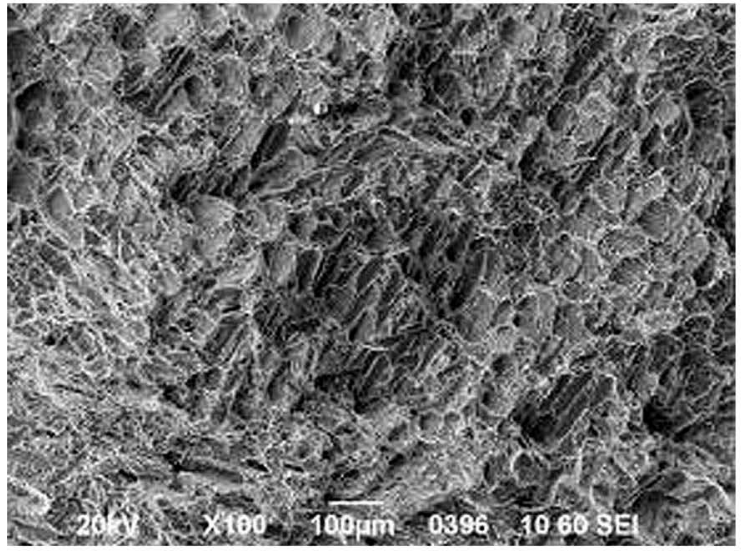

(c)

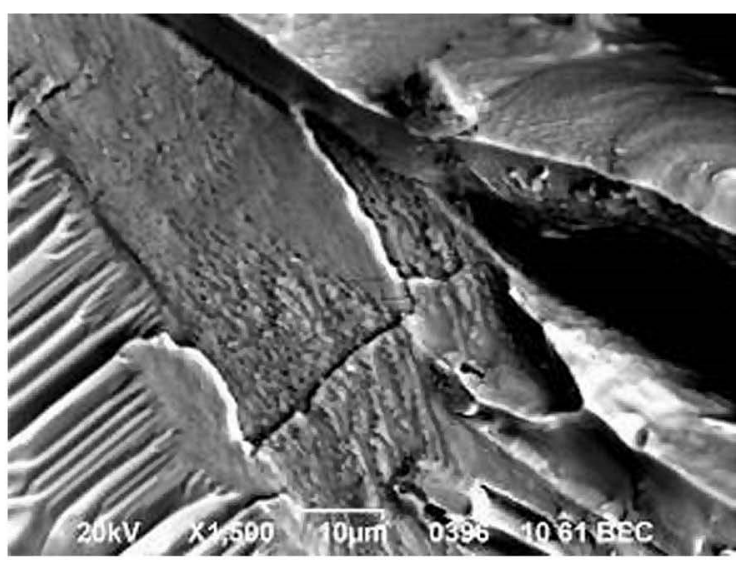

(b)

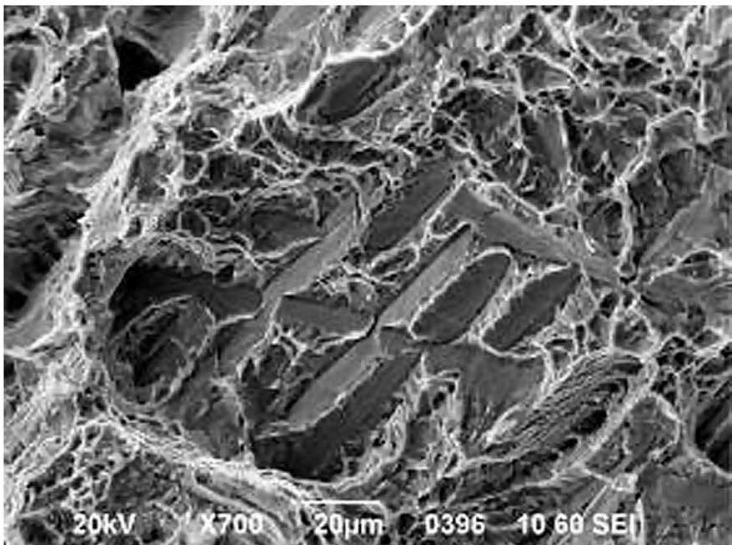

(d)

Figure 10. The morphology of fracture surface of titanium samples with oxygen content of 0.27 wt.-\% ((a), (b)) and 0.053 wt.-\% ((c), (d)), revealed by SEM.
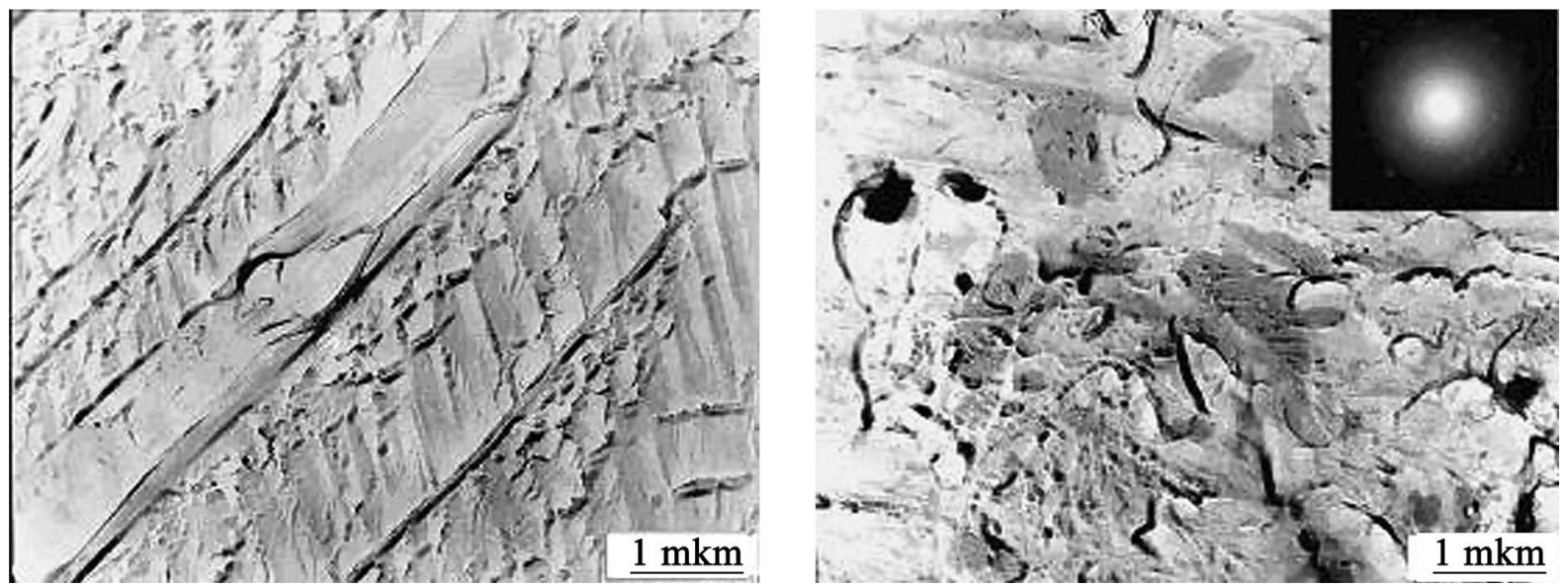

Figure 11. The surface morphology of the fracture of titanium with an oxygen content of 0.053 wt.-\% (left) and 0.27 wt.- $\%$ (right), revealed by TEM $(\times 10,000)$.

gen content in titanium provides the development of $\beta \rightarrow \alpha$ transformation by shear mode with the formation of needle-shaped microstructure. In result of intensified nucleation of needle shape crystals of $\alpha$ '-phase with increasing oxygen contents in the metal, a more advanced multilevel structure consisting of needles with various sizes is formed, which further refines the structure of the produced titanium. 


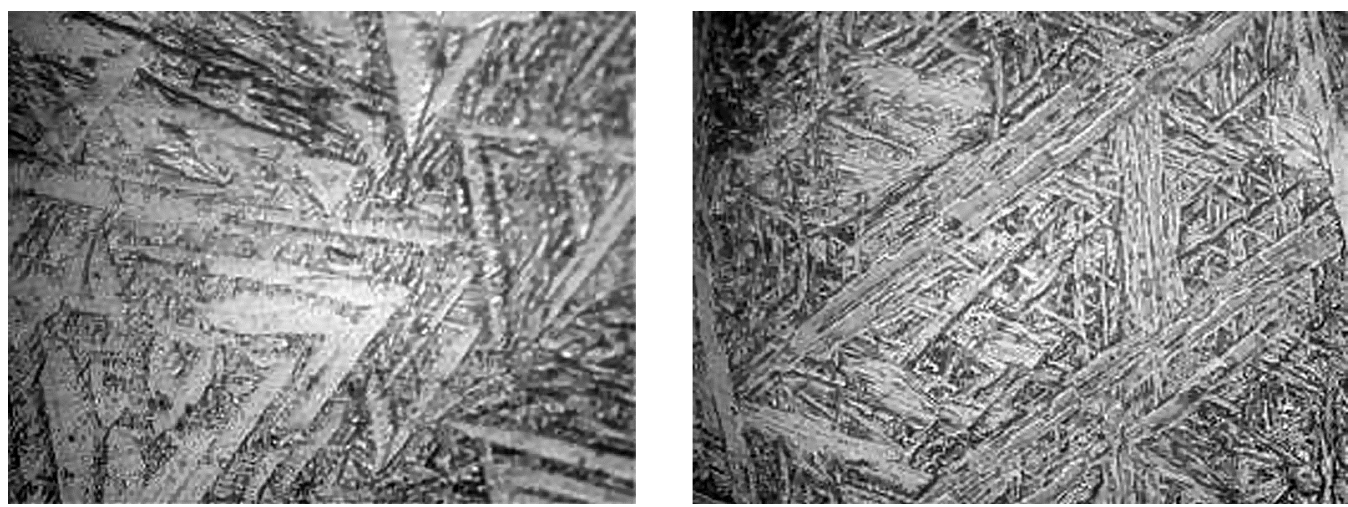

Figure 12. The structure of titanium containing 0.053 wt.-\% (left) and 0.27 wt.- $\%$ (right) oxygen, after quenching, $\times 500$.

\section{Conclusions}

1) In this paper, the structure and properties of titanium that was alloyed by oxygen from reaction mass residues, from the gas phase and titanium oxide powder during chamber electroslag remelting of titanium sponge were studied. It can be observed that in the investigated range of concentrations from $0.053 \mathrm{wt} .-\%$ to $0.73 \mathrm{wt} .-\%$, oxygen affects the formation of phases and changes their morphology. Thus, in as-cast condition at concentrations less than $0.11 \mathrm{wt} . \mathrm{\%}$ oxygen in the metal, a homogeneous single-phase structure with polyhedral grains of $\alpha$-phase is formed, which is typical for technical titanium. In samples with oxygen contents above $0.22 \mathrm{wt} . \mathrm{\%}$, the formation of a needle-shaped microstructure, which is typical for $\alpha$-phase can be observed. A rise of the oxygen content from 0.053 wt.- $\%$ to 0.73 wt.- $\%$ significantly increases the hardness (from 120 to $350 \mathrm{HB}$ ) and the strength of titanium (from 380 to $795 \mathrm{MPa}$ ).

2) It is established that in the equilibrium (annealed) state, an inhomogeneous solid solution of oxygen in $\alpha$-Ti evolves, consisting of areas with different etchability. The microhardness in the dark etched areas remains constant at $2760-2850 \mathrm{MPa}$, whereas the microhardness in the oxygen-enriched light areas is increased by 1.3 times. The average size of the structural constituents (elongated oriented grains arranged in a type of "basket weave") rises by 250 to 300 percent.

3) It was found that in the investigated range of oxygen concentrations (0.053 - 0.73 wt.-\%), the formation of compact inclusion compounds of TixOy is not observed during tempering of samples that were quenched from the single-phase $\beta$-field. The main structural transformation during heating after quenching is the recrystallization in the form of a needle structure. An increased oxygen content in the metal leads to an inhibition of the recrystallization process.

4) It was established that the embrittlement of titanium of the binary system titanium-oxygen is caused by the formation of coarsened as-cast structure and not by the precipitation of dispersed phases. With increasing oxygen concentrations, the character of crack development in as-cast metal changes from transcrystalline to intercrystalline fractures.

\section{References}

[1] Elias, C.N., Lima, J.H.C., Valiev, R. and Meyers, M.A. (2008) Biomedical Applications of Titanium and Its Alloys. JOM, 60, 46-49.

[2] Ryabtsev, A.D. and Troyanskyy, A.A. (2005) Electroslag Remelting of Metals and Alloys under Fluxes with Active Additions in Furnaces of Chamber Type (ChESR). Proceeding of the 2005 International Symposium on Liquid Metal Processing and Casting “LMPC 2005”, Santa Fe, USA, 18-21 September 2005, 227-232.

[3] Ryabtsev, A.D. and Troyanskyy, A.A. (2005) The Electroslag Remelting of Metals and Alloys under Fluxes with Active Additive in the Furnaces of Chamber Type. Electrometallurgy, No. 4, 25-32.

[4] Ryabtsev, A.D., Troyanskyy, A.A. and Davidov, S.I. (2009) The Refining of Titanium from Oxygen and Nitrogen during Electroslag Remelting. Modern Electrometallurgy, No. 4, 1-3.

[5] Troyanskyy, A.A. and Ryabtsev, A.D. (2007) About Works of Donetsk National Technical University on Electroslag Melting and Refining of Titanium. Titanium, No. 1, 28-31.

[6] Benz, M.G., Meschter, P.J., Nic, J.P., Perocchi, L.C., Gigliotti, M.F.X., Gilmore, R.S., Radchenko, V.N., Ryabtsev, 
A.D., Tarlov, O.V. and Pashinsky, V.V. (1999) ESR as a Fast Technique to Dissolve Nitrogen-Rich Inclusions in Titanium. Materials Research Innovations, No. 6, 364-368.

[7] Ryabtsev, A.D. and Troyansky, A.A. (2008) Chamber Electroslag Remelting (ChESR)—A New Method for Enhanced Quality Ingot Production. Proceedings of the Third Biennial Academic Conference (Baosteel BAC 2008), Shanghai, 26-28 September 2008, 39-42.

[8] Reitz, J., Friedrich, B. and Stoephasius, J.C. (2007) Fundamentals of Deoxidation Behaviour of Ti-Alloys by Chamber ESR with Ca-Reactive Slags. Proceedings of the European Metallurgical Conference (EMC 2007), 11-14 June 2007, Düsseldorf, 1377-1391.

[9] Friedrich, B., Reitz, J. and Stoephasius, J.C. (2009) PESR Processing of TiAl-Electrodes Made by Aluminothermic Reduction. Proceeding of the 2009 International Symposium on Liquid Metal Processing and Casting "LMPC 2009". Santa Fe, USA, 20-23 September 2009, 295-301.

[10] Ryabtsev, A.D., Davidov, S.I., Troyanskyy, A.A., Shvarzman, L.Ya., Ryabtseva, O.A., Pashinsky, V.V. and Feofanov, K.L. (2007) The Obtaining of Titanium of Raised Toughness by the Way of Alloying by Oxygen during Chamber Electroslag Remelting. Modern Electrometallurgy, No. 3, 3-6.

[11] Ratiev, S.N., Ryabtseva, O.A., Troyanskyy, A.A., Ryabtsev, A.D., Davidov, S.I. and Shvarzman, L.Ya. (2010) The Alloying of Titanium by Oxygen from the Gas Phase during Chamber Electroslag Remelting of Titanium Sponge. Modern Electrometallurgy, No. 2, 8-12.

[12] Ryabtsev, A.D., Troyanskyy, A.A., Ratiev, S.M., Pashynskyy, V.V. and Snizhko, O.A. (2011) The Alloying of Titanium by Oxygen in the Process of Chamber Electro-Slag Remelting. Proceeding of the 2011 International Symposium on Liquid Metal Processing and Casting “LMPC 2011”, Nancy, 18-21 September 2011, 39-42.

[13] Ryabtsev, A.D. (2011) The Refining and Alloying of Titanium in the Process of Chamber Electro-Slag Remelting. In: Friedrich, B. and Troyanskyy, A.A, Eds., Slags and Fluxes in Modern Metallurgy: Proceeding of the International Workshop on Metal-Slag Interactions, Shaker Verlag, Aachen, 175-188.

[14] Ryabtsev, A.D., Troyanskyy, A.A., Davidov, S.I., Pashinsky, V.V., Snizhko, O.A., Ratiev, S.M. and Leoha, F.L. (2012) The Possibilities of Chamber Electroslag Remelting to Obtain a Commercial Purity Titanium. Modern Electrometallurgy, No. 1, 7-11.

[15] Bumps, E.S., Kessler, H.D. and Hansen, M. (1953) The Titanium-Oxygen System. Transactions of the American Society for Metals, No. 45, 1008-1028.

[16] Murray, J.L. and Wriedt, H.A. (1987) The O-Ti (Oxygen-Titanium) System. Bulletin of Alloy Phase Diagrams, No. 8, 148-165.

[17] Chase Jr., M.W., Curnutt, J.L., Prophet, H., McDonald, R.A. and Syverud, A.N. (1975) JANAF Thermochemical Tables, 1975 Supplement. Journal of Physical and Chemical Reference Data, No. 4, 175.

[18] Driz, M.E. (1997) The Properties of Elements. Metallurgiya, Moscow, 432 p.

[19] Donachie Jr., M. (2000) Titanium: A Technical Guide. 2nd Edition, ASM International, Materials Park, 369 p.

[20] Lutjering, G. and Williams, J.C. (2007) Titanium. 2nd Edition, Springer, Heidelberg, 431 p. 